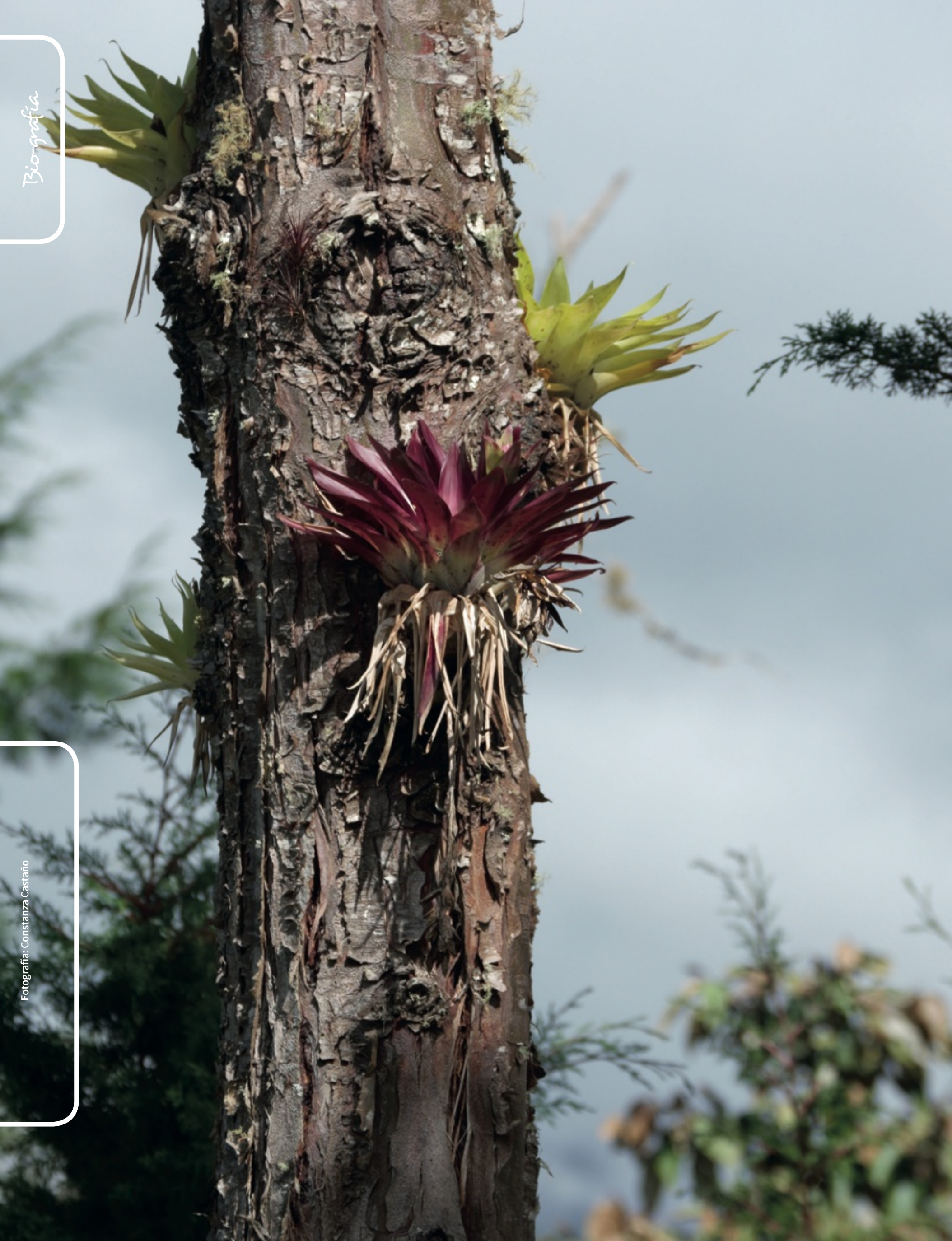




\section{VIAJE DE UN NATURALISTA EN EL MUSEO DE LA CIENCIA Y EL JUEGO. EXPERIENCIAS DE DIVULGACIÓN DE LA BIOLOGÍA ATRAVÉS DE LA LÚDICA}

\section{The journey of a naturalist at the Museum of Science and Game. Experiences of divulgation of biology through ludic activities}

Fecha de recepción: 16 de agosto de 2013

Fecha de aprobación: 13 de diciembre de 2013

\section{Juan Pablo González-Medina ${ }^{1}$}

\section{Resumen}

La presente Biocrónica tiene el objeto de hablar sobre objetos; De compartir algunos resultados de mis actividades como biólogo y creativo en el Museo de la Ciencia y el Juego de la Universidad Nacional de Colombia haciendo especial alusión a los objetos pertenecientes a exposiciones itinerantes y a las actividades lúdicas que poseen un énfasis temático en biología. Estos objetos y talleres han sido utilizados en diferentes escenarios, especialmente en entidades públicas como colegios distritales, pero también en otros espacios subestimados donde ocurren encuentros interculturales como son las Juntas de Acción Comunal. Se exponen brevemente las características de cada uno de los objetos y de los talleres, resaltando el aporte que constituyen en la enseñanza de la biología para el país en su dimensión no formal.

\section{Palabras clave}

Museo, lúdica, objetos de exposición, biología.
El naturalista sufre aquí la agradable molestia de no poder caminar cien metros sin quedarse inmovilizado al contemplar algo nuevo y maravilloso.

Charles R. Darwin, Viaje de un naturalista alrededor del mundo,1839

1. Biólogo y Estudiante de la Maestría en Estudios Sociales de la Ciencia de la Universidad Nacional de Colombia; Docente de la Universidad Piloto de Colombia. juanpablo717@gmail.com 


\section{El M. C. J. Ludus: Un barco muysingular}

Encontrándome varado en una isla de concreto, un viejo amigo, ${ }^{2}$ proveniente de aquella tierra extraña llamada La Comarca, reconociendo mi naufragio, me indicó con mucho atino que dirigiera mi atención a las coordenadas $30^{\circ} 45^{\prime} 03^{\prime \prime}$ norte, $31^{\circ} 65^{\prime} 44^{\prime \prime}$ ' oeste, donde me aseguró encontraría un viejo barco ¡de casi 300 años!, que seguramente podría requerir de mis servicios.

Aprovechando la marea - ¡que ya mareado me tenía!fui con prisa al sitio indicado, encontrando un lugar que varios tesoros poseía y que inesperados viajes me tenía. El nombre de la longeva embarcación es M. C. J.Ludus, ${ }^{3}$ encallada en Bahía Nacho, desde tiempos ya lejanos.

Al servicio me puse entonces del capitán Betancourt, ${ }^{4}$ viejo lobo de mar, que ya conocía el mundo, los siete mares y hasta más. Del capitán los marineros en coro decían:

\section{De aspecto férreo el capitán, por tantos viajes ya curtido, siempre manda con afán, pero con tono divertido.}

Nos contaba de sus viajes, de ida y vuelta hacia Ítaca, y a veces se jactaba de aquella vez que al mismo Ulises había vencido en el arte del tiro al blanco. Nos contó que una vez vio a las musas en persona, y que dicha aparición divina lo motivó para construir con sus propias manos, y las de muchos otros queridos compañeros de destino - algunos ya con Poseidón-, la embarcación en la que nos encontrábamos ahora.

"Aquí todos somos remeros" me dijo el capitán, "y para hacer andar la nave, con toda la tripulación hay que contar". Nada homogénea era, y allí radicaba su funcionalidad, generando cosas nuevas, en una creación siempre comunal.

"De bichos y plantas sabes y por tanto has de ser el encargado de efectuar la colección de cuanta cosa se mueva durante tu instancia en este barco" sentenció

2. Ludwig Van Jiménez. Biólogo y Magíster en Ciencias Biológicas de la Universidad Nacional de Colombia.

3. Museo de la Ciencia y el Juego de la Universidad Nacional de Colombia. Museo interactivo con casi 30 años de funcionamiento, el más antiguo de Colombia.

4. Julián Betancourt Mellizo. Físico, fundador, amigo y director del Museo de la Ciencia y el Juego. el viejo lobo de mar. "Con la brújula de la imaginación y el astrolabio de la creatividad has de contar, pero que nunca se te olvide tu conocimiento previo, que aquí te ha de ayudar".

La colección encargada no era para nada normal, porque lo que se capturaba no eran bestias de verdad, sino ideas, que plasmadas en objetos y performances, algunas historias querían contar.

\section{El Museo de la Ciencia y el Juego}

El juego es una actividad que puede favorecer el intercambio intercultural. En su seno, se puede vincular a afros, blancos, indígenas, raizales, comunidad LGBTI, religiosos, ateos, en fin, seres humanos con diversas interpretaciones de la realidad, que tienen en común una naturaleza lúdica. Homo ludens sentenciaría Huizinga, oración que expresa lo natural, sin importar la cultura, del acto de jugar.

La presente biocrónica tiene como objetivo mencionar, de manera tangencial, algunas de las actividades realizadas concernientes a la divulgación de la biología durante mi permanencia en el Museo de la Ciencia y el Juego de la Universidad Nacional de Colombia (MCJ de aquí en adelante), ${ }^{5}$ lugar que desde su creación ha generado espacios de intercambio cultural, a través de sus actividades lúdicas y divulgativas. Cabe resaltar que este lugar ha sido sitio donde varios biólogos y licenciados de la biología han podido crear diferentes talleres y objetos de exposición con fines divulgativos, sin embargo, solo mencionaré aquellas experiencias en las que participé activamente. Algunas actividades realizadas anteriormente relacionadas con la biología y con otras ciencias están reportadas en la revista Museo Lúdica y en la Cartilla de Biología diseñada para el proyecto Re-Creodurante la década de los noventa.

El mcj tiene como misión llevar a cabo planes, programas y proyectos en el campo de la popularización y apropiación ciudadana de la ciencia y la tecnología, buscando eficacia social en sus acciones, gracias a herramientas que tienen como base el empleo de la lúdica y el juego. Esta filosofía institucional ha hecho que el museo participe en varios proyectos dirigidos a públicos con dife-

5. Para más información sobre el mcj invito al lector a visitar la página web www.cienciayjuego.com donde podrá descargar artículos gratuitos y saber un poco más de su experticia y proyectos en el campo de la lúdica y la divulgación del conocimiento. 
rentes formaciones académicas y siempre ha buscado la formación y fortalecimiento de competencias culturales básicas, como la observación, la exploración, la comparación, la reflexión y la argumentación, siguiendo el esquema conceptual desarrollado principalmente por su director, Julián Betancourt.

Varias de las temáticas tratadas por el MCJ abarcan, generalmente, componentes científicos y culturales, lo que hace que los diseñadores de los mismos - un grupo interdisciplinario de profesionales en ciencias naturales, ciencias humanas, diseñadores industriales y gráficos - tengan un reto extra al procurar hacer del objeto de exposición, algo con poder de atracción, retención, diversión y que no desfigure de manera esencial el saber con el que se le relaciona.

\section{Objetos relacionados con la biología que hacen parte de las exposiciones interactivas del MCJ}

Las exposiciones interactivas están compuestas por objetos, guías de uso de los mismos, y afiches con información expuesta de manera tal que procura ser clara, sintética y atractiva, para hacer de la temática contenida en estas, algo más accesible a los públicos visitantes.

Las guías asociadas a los objetos poseen, generalmente, un "marco teórico disfrazado", es decir, un texto que relaciona conceptos científicos con experiencias cotidianas y la instrucción del juego como tal. Las guías tienen como regla tres aspectos a considerar: 1) Lenguaje sencillo, cotidiano; 2) Gráficos que faciliten el entendimiento y hagan de la guía, a su vez, un objeto atractivo; 3) La menor cantidad de texto pero con las indicaciones mínimas para entender el juego y su temática.

Los objetos expositivostambién pretenden ser una invitación a la paidia y al ludus, siguiendo el lenguaje de Caillois (1986), lo que hace necesario un trabajo interdisciplinario (diseñadores gráficos e industriales, académicos, y población en general) que asegure un objeto de exposición atractivo, motivador de procesos de aprendizaje y divertido.

A "lomo de mula" y "viajando en chalupa", literalmente, han viajado las Maletas del Museo a lugares de difícil acceso donde poblaciones de diferentes etnias, varias de escasos recursos económicos, pueden conocer una exposición interactiva sin la necesidad de ir a una ciudad ni pagando un alto costo, ya que el préstamo es gratuito. Estas maletas son exposiciones interactivas itinerantes que han viajado a lo largo y ancho del país. Cabe resaltar que recibieron en el año 2011 el PremioRedPOP 2009-2010,categoría institucional, otorgado por la Red de Popularización de la Ciencia y la
Tecnología en América Latina y el Caribe, RedPOP, entidad auspiciada por la Unesco.

A continuación mencionaré, de manera breve, algunos aspectos de los objetos pertenecientes a exposiciones interactivas relacionadas con la biología de manera directa (la mayoría pertenecen al programa Maletas del Museo; para más información sobre este interesante programa visitar la página www.cienciayjuego.com).

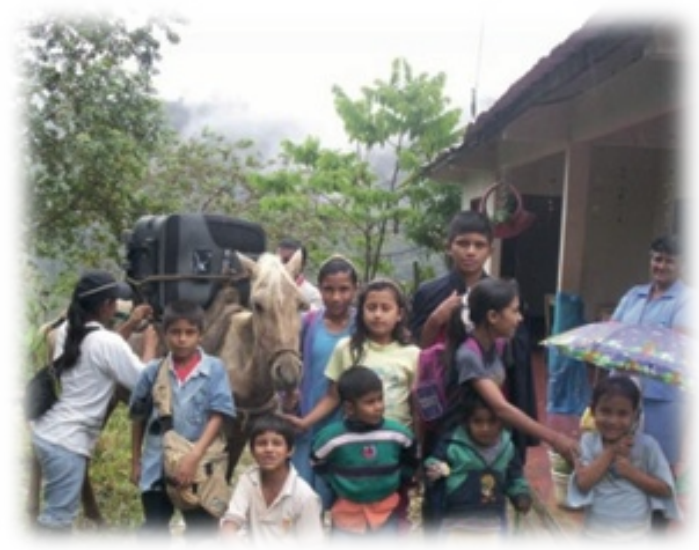

Figura 1. Exposición itinerantea

"lomo de mula" del programa Maletas Viajeras.

Fuente: Fotografía tomada en Florencia (Caquetá). @ @ MCJ.

\section{El árbol}

Temas: Sistemática filogenética, morfología comparada y diversidad biológica.

Está compuesto por una estructura en forma de árbol, que se puede poner verticalmente, y nueve fichas con figuras de artrópodos y palabras relacionadas con los mismos. El objetivo principal, teniendo en cuenta unas características compartidas, es el de colocar cada artrópodo en el lugar adecuado, generando así una hipótesis de relación filogenética que será validada con una prueba relacionada con un texto sobre los artrópodos y su éxito evolutivo.

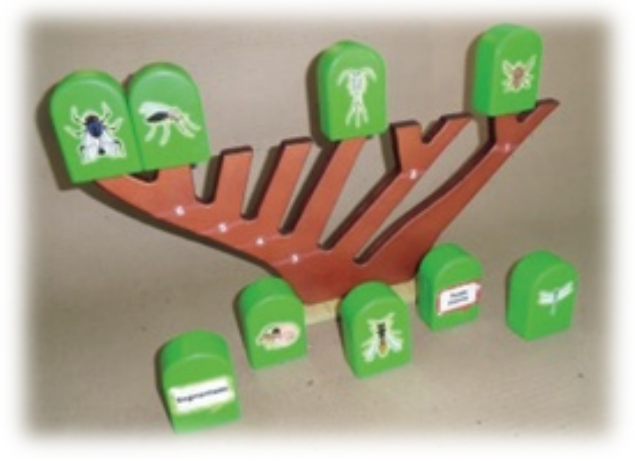

Figura 2. El árbol. @ MCJ. 
Como indica Araujo y Roa (2011), haciendo alusión a las reflexiones de Baum y Ofner (2008), los árboles filogenéticos son una estrategia pedagógica importante "para que el estudiante/investigador apropie los conceptos claves de la evolución, mediante el uso/construcción de los árboles" pero no son utilizados frecuentemente, tanto en educación formal como no formal. Estos autores indican que la utilización de ciertos árboles filogenéticos, como el de los tetrápodos, permite al profesor de biología enlazar, durante todo el año, las diferentes temáticas de la clase de biología. El juego el árbol, por tanto, constituye un facilitador del aprendizaje, de posible uso en educación formal, y un aporte para la enseñanza del pensamiento sistemático y filogenético, ejercitándose las competencias de observación, ya que para resolver el juego el sujeto debe inspeccionar minuciosamente los diferentes artrópodos para identificar sus semejanzas y diferencias, $y$, a su vez, se requiere comparar para poder resolver el juego.

\section{La historia de la vida}

Temas:Ordenamiento de eventos históricos, complejidad biológica y fósiles.

Rompecabezas deslizable de doble cara. En el lado $A$, encontramos que las fichas corresponden a diferentes eventos que han acontecido en la historia del planeta Tierra, desde su formación hasta la aparición de organismos como las aves, los primates y las plantas con flores. En el lado $B$, se deberá armar la imagen de un fósil de ammonite, fósiles que en parte constituyen evidencia para poder reconstruir la historia de la vida.
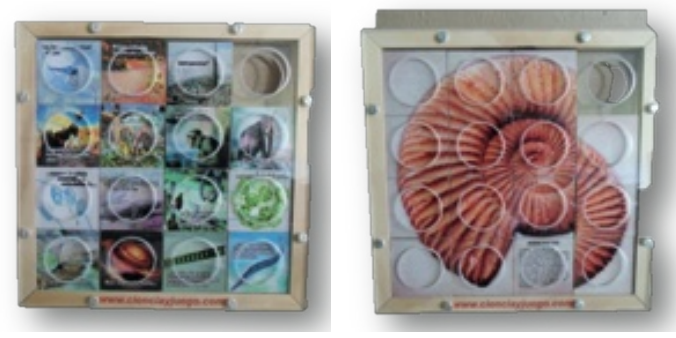

Figura 3. La historia de la vida.Lado A (izquierda). Lado B (derecha). @ MCJ.

Para poder resolver este juego, debe existir un reconocimiento de una lógica narrativa en la biología. Para que haya habido un organismo multicelular, por ejemplo, debió primero existir uno unicelular, y antes de eso tuvo que originarse la vida, y antes el sistema solar. El estudiante recurre entonces al conocimiento aprendido sobre eventos evolutivos, como la generación de innova- ciones evolutivas, extinciones, entre otros, y a su lógica narrativapara ordenar coherentemente los eventos evolutivos presentados en el deslizable. Cuando uno de los lados del rompecabezas es armado, el otro se desarma, por lo que los jugadores se encontrarán siempre con un rompecabezas que resolver.

\section{Fractales en la naturaleza}

Temas: Fractales naturales, fractales matemáticos y morfología.

Rompecabezas que se encuentra en un plano polar que solo se podrá armar correctamente si el jugador logra responder adecuadamente una serie de preguntas de selección múltiple relacionadas con los fractales en la naturaleza y la complejidad geométrica de los seres vivos. Cada respuesta tiene asociado un grado $\left({ }^{\circ}\right)$. Si contesta correctamente, entonces podrá colocar cada lamina en el grado correcto y podrá observar la figura de Brassica oleracea, una planta que es un fractal natural. Este es un objeto que invita al sujeto a reflexionar sobre las relaciones entre disciplinas científicas, como la matemática y la biología, en la interacciónpuede que el sujeto logre apreciar cómo un fenómeno natural puede ser visto desde diferentes perspectivas temáticas.

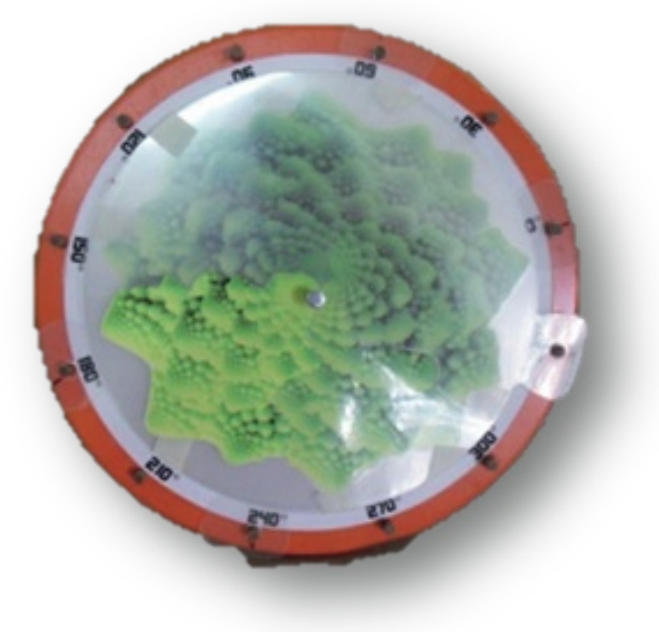

Figura 4.Fractales en la naturaleza. @ MCJ.

\section{EncADeNando}

Temas:Complementariedad de la hebra de adn, especificidad biomolecular y biología molecular. 


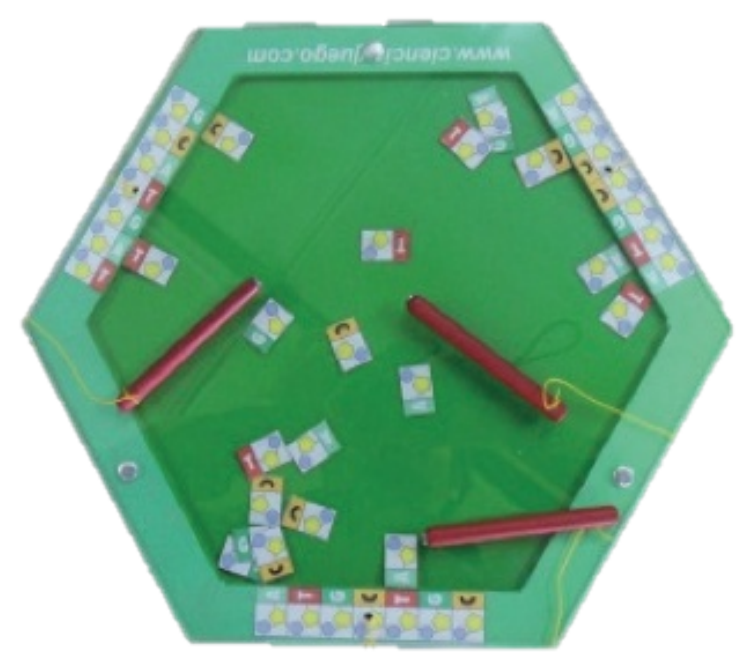

Figura 5.EncADeNando. (c) MCJ.

Tablero con fichas magnéticas (nucleótidos) y lápices imantados (enzimas) que le permitirá a los jugadores complementar varias hebras de adn que se encuentran esquematizadas en las paredes del tablero, teniendo cuidado de emparejar adecuadamente las bases nitrogenadas. Recordando siempre que

\section{Adenina con Timina Citosina con Guanina son parejas siempre unidas, en la hebra de la vida.}

la especificidad del lenguaje bioquímico y su nivel de abstracción puede no hacer de esta disciplina algo muy atractivo para muchas personas, lo que dificulta la construcción de conceptos y terminología propia de la disciplina. Con aproximaciones como la indicada en este juego de competencia se espera que se asimile más fácilmente que las bases nitrogenadas no interactúan de manera totalmente aleatoria, que existen unas tendencias que son vitales para el funcionamiento de los procesos moleculares, como la replicación del ADN, en donde se debe reconocer la especificidad de interacción entre sus componentes.

Los objetos mencionados hasta ahora hacen parte de la Maleta Rumbo UN [siglas de Universidad Nacional de Colombia], creada dentro del marco del Proyecto de Divulgación de la Oferta Curricular de los Programas de Pregrado y Postgrado de la UN. Los textos de las guías de los juegos de la Maleta Rumbo UN, a diferencia de los textos que acompañan otras exposiciones, son más extensos y de mayor complejidad, sin embargo, esto no fue realizado de manera inadvertida, ya que uno de los propósitos de esta maleta es dar a entender a los estudiantes que para resolver estos juegos es indispensa- ble poseer una buena comprensión de lectura, habilidad que debe ser ejercitada y que es indispensable, por ejemplo, para que un aspirante que realiza el examen de admisión de la Universidad Nacional de Colombia tenga mayor probabilidad de ingresar a la institución (uno de los propósitos de esta exposición es la de invitar e incentivar a diferentes personas, principalmente estudiantes de ciclo cinco, a que conozcan la universidad y se presenten a la misma si consideran que existe un programa que les llame la atención).

\section{La pícara hormiga de Mutis}

Temas:Historia de la expedición botánica y morfología de insectos.

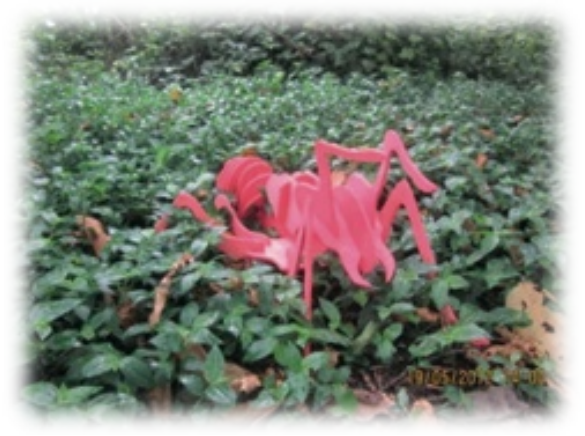

Figura 6.La pícara hormiga de Mutis. @ MCJ.

Armable de madera constituido por once piezas que forman un rompecabezas tridimensional de una hormiga. Este juego hace parte de la exposición "Mutis, el maestro y su época" que se encuentra en la Sede Tumaco de la Universidad Nacionalde Colombia, y se basó en la siguiente cita del naturalista español José Celestino Mutis (citada por Granada,Orozco, Bonilla y Fernández, 1995, p. 36):

Hoy he empleado gran parte de la mañana en reconocer todas las hormigas que he recogido en esta temporada, comparándolas con otras que tenía guardadas. Es indecible el desconsuelo que tuve al ir abriendo los papeles en que las tenía depositadas, pues una hormiga pequeña y voraz entró en la colección y maltrató la mayor parte de las hormigas que con tanto trabajo había recogido.

La guía del juego insta a que el participante arme "la pícara hormiga" que supuestamente devoró las colecciones de Mutis, ejercitando de paso, conocimientos mínimos sobre el plan corporal de los insectos, realizando una observación minuciosa de formas, que teniendo en cuenta principios mínimos de funcionalidad, dan origen a un todo con coherencia entre las partes. 
¿A qué grupo pertenezco?

Temas:Sistemática, taxonomía y entomología.

¡Un ventarrón sacudió el gabinete donde José Celestino Mutis estaba clasificando algunos de los insectos y arácnidos que ha recogido durante la expedición botánica y se revolvieron accidentalmente las etiquetas donde se indican los nombres científicos de los grandes grupos a los cuales pertenecen!

En este juego, que hace parte de la exposición itinerante de gran formato (exposiciones que requieren un espacio mínimo de $200 \mathrm{~m}^{2}$ ) nombrada "Mutis, el maestro y su época", el jugador deberá ayudar a nuestro naturalista a clasificar correctamente los artrópodos, colocando en frente de cada estante la etiqueta que considera adecuada basándose en unas características morfológicas. Aquí se introduce al público al quehacer del naturalista, que para saber más del mundo natural debe realizar colecciones biológicas y clasificar adecuadamente las diferentes especies colectadas, dependiendo de ciertas características, especialmente morfológicas para el presente caso. La competencia a reforzar principalmente es la comparación de entidades y, posterior a un análisis considerando características compartidas, el sujeto puede arriesgar a establecer una organización de las entidades en categorías abstractas.

\section{Objetos, lúdica y divulgación}

Los objetos, sea en el ámbito museístico o en otro contexto, no poseen un significado totalmente independiente o absoluto. Este aspecto semiótico de la experiencia con el objeto hace que la persona interesada en realizar divulgación científica por medio de exposiciones interactivas no deba descuidar varios de los contextos socioculturales que posee la población objetivo.

Diferentes autores han venido reconociendo que la interacción con los objetos de una exposición no es un simple tratar de adivinar el "mensaje escondido" del objeto o de la colección. No hay un único mensaje; hay varios mensajes posibles, debido a que, como indicaba Annis (1986), "los objetos aceptan y reflejan los significados que el visitante les sabe atribuir". El autor indica que la interacción objeto-espectador puede ser pensada como un conjunto de espacios: onírico, pragmático y cognoscitivo, haciendo alusión a aspectos no racionales, sociales y lógicos, respectivamente. Cuando se explora la existencia de estos espacios de significación simultáneos, interactuantes e inevitables, el divulgador científico reconoce que, lo racional (el espacio cognoscitivo) no es lo único que entra en juego, y que la experiencia de la interacción se verá enriquecida si se genera significación apreciable en los otros espacios. En términos prácticos el divulgador debe prestar atención aaspectos estéticos de los objetos y guías, el tipo de lenguaje utilizado, y las dinámicas a las cuales invita el objeto y la guía, que para el caso de las exposiciones interactivas, conllevan actividades lúdicas que pueden realizarse de manera grupal o individual. Parte de estas consideraciones teóricas y prácticas se reflejan en los objetos mencionados y en las experiencias relacionadas con los mismos. Aunque el MCJ a través de sus exposiciones interactivas no pretende transmitir un saber determinado, sí promueve ámbitos donde se generan prácticas educativas, que, siguiendo a Montaldo (2001), hacen que los sujetos reciban una cantidad de indicadores y un sistema de signos, a partir de los cuales se generan roles, relaciones jerárquicas, ordenamiento del espacio físico, entre otros (Montaldo, 2001), además de promover, mediante una práctica no académica, el refuerzo o adquisición de conceptos de la biología - para el presente caso-mediante la interacción lúdica con los objetos.

Varios de los objetos presentados pueden considerarse juegos y poseen "sistemas de reglas" (Cailloise, 1986) que se relacionan con un contenido biológico como, por ejemplo, en el juego EncADeNando, en el que se debe emparejar las fichas de nucleótidos siguiendo la correspondencia adenina-timina, citosina-guanina. Vemos que varias de las reglas se inspiran en mecanismos, correspondencias o metáforas biológicas, de tal manera que el jugador que sigue las reglas, en algunas ocasiones, simula procesos biológicos para poder ganar el juego. Sin embargo, en la interacción objeto-sujeto no siempre se da una interacción "esperada" y es donde el juego como estrategia de divulgación y/o enseñanza falla en el espacio cognoscitivo aunque pueda generar significados de apreciación hacia el conocimiento científico, así no haya una comprensión del mismo, esto debido al valor adjudicado a la experiencia lúdica y a la asociación de la experiencia vivida con el tema científico.

\section{Los talleres del MCJ}

El MCJ también ofrece talleres, que son actividades en donde un mediador con conocimiento en un área específica, desarrolla una charla, utilizando un lenguaje ameno, entretenido, fácil de seguir, haciendo uso de lo cotidiano y una actividad práctica, que en la mayoría de los casos se base en el juego, para estimular la curiosidad y la empatía por el conocimiento.

A continuación describiré varios de los talleres con unos fuertes componentes en el área de la biología, diseñados y ejecutados en varios proyectos realizados por el MCJ 
durante el año 2012 principalmente, viéndose beneficiados una población de aproximadamente 1862 personas según los registros. La mayoría de estos talleres fueron dictados a población estudiantil de primaria y secundaria en dieciséis colegios distritales (Robert Kennedy, Rembrandt, Las Mercedes, Centro Educativo San Juan Bosco, San José Norte, Nidia Quintero de Turbay, Simón Bolívar, Tomás Cipriano de Mosquera, Juan del Corral, República de Guatemala, Los Alpes, Guillermo León Valencia, San José Sur Oriental, Francisco Matiz, República del Ecuador y Pantaleón Gaitán).

\section{Entre genes y emociones}

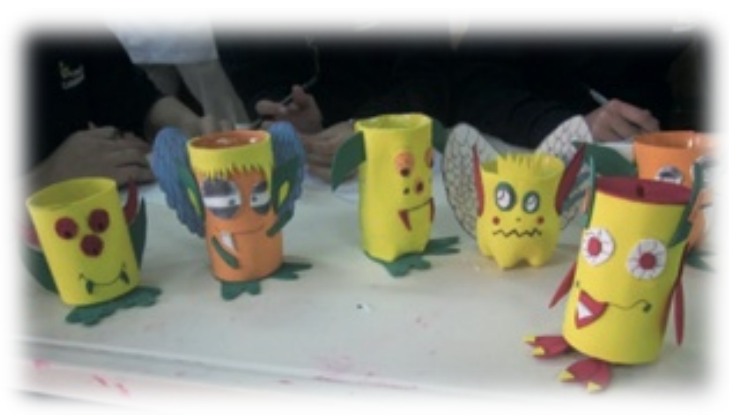

Figura 7.Entre genes y emociones.

Fuente: Fotografía tomada en el Instituto Educativo Distrital Las Mercedes durante el proyecto Ciencia cotidiana y los domingos de la Ciencia (2012) ( ) MCJ.

Mencionando personajes como los X-Men, Spider-Man y otros seres de la fantasía contemporánea, se presentan ciertos conceptos básicos de la ciencia de la herencia y se hace alusión a los mitos y posibilidades de la ingeniería genética. Posteriormente, se realiza una actividad en la que se simula la adquisición de un genotipo determinado que, mediante el uso de una tabla de correspondencia, indica un fenotipo que podrá plasmar manualmente generando seres hipotéticos con variabilidad poblacional. Para más detalles sobre este taller revisar la referencia González-Medina (2011) de acceso gratuito en www.cienciayjuego.com.

\section{¡En extinción!}

Se presentan algunos de los eventos de extinción y sus protagonistas a lo largo de la historia de la vida, así comocausas y posibles efectos en la pérdida de la biodiversidad por el impacto antrópico en los ecosistemas. Las actividades fueron de dos tipos: armar, a partir de un fósil hipotético, la estructura ósea de un dinosaurio y la generación de un fósil en yeso, utilizando figuritas de diferentes seres vivos extintos. Esta actividad genera un acercamiento a los estudiantes a la actividad del paleontólogo, mostrando que ciertas actividades científicas son verdaderas resoluciones de rompecabezas y que requieren de un conocimiento especializado.

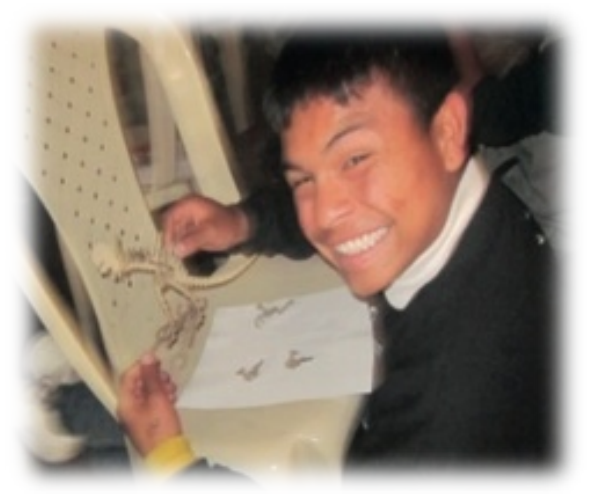

Figura 8. En extinción.

Fuente: Fotografía tomada en el Centro Educativo San Juan Bosco durante el proyecto Ciencia cotidiana y los domingos de la Ciencia (2012) (c) MCJ.

\section{Evolución}

La teoría evolutiva, la evidencia a su favor, los mitos sobre la misma y el mecanismo de selección natural son presentados al público haciendo alusión a ejemplos y personajes cotidianos. En la actividad se divide el grupo y a cada subconjunto se le da un tipo diferente de utensilio (cuchara, tenedor, palo de paleta, cucharita) para capturar semillas de frijol en un área determinada y con un tiempo límite. El proceso se itera y se va registrando la cantidad de frijoles capturados por cada subgrupo, movilizándose más individuos a los subgrupos que obtienen más recursos ya que se espera que aumenten de tamaño por dejar más descendencia. Actividades análogas para ejemplificar el actuar de la selección natural mediante una sencilla simulación se pueden apreciar en Andrade et al. (2006) y en Burton y Dobson (2009).

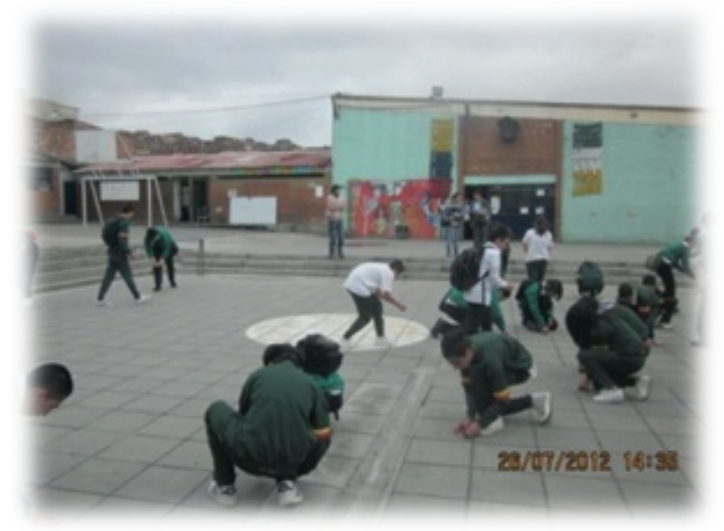

Figura 9. Evolución.

Fuente: Fotografía tomada en el Instituto Educativo Distrital San José Sur Oriental durante el proyecto Programa Escuela Ciudad Escuela - Expediciones Pedagógicas (2012)@ MCJ. 


\section{Biósferas}

Las relaciones entre los seres vivos y su ambiente, así como los diferentes niveles de organización y multiplicidad de interacciones ecológicas se presentan de manera amena y los asistentes elaboran pequeñas biosferas, tratando de simular un ambiente semicerrado con componentes bióticos y abióticos que en su conjunto representan un pequeño ecosistema. Los participantes logran hacer una manualidad que no solo les refuerza algunos de los conceptos tratados sino que, además, se llevan un recuerdo de la actividad que puede servir de refuerzo y con fines estéticos.

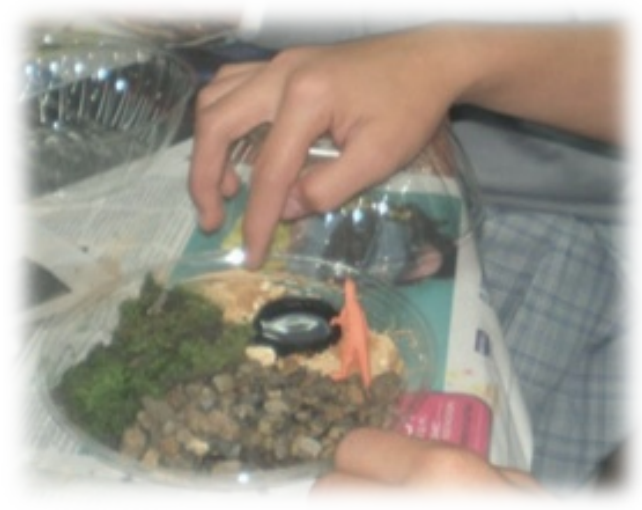

Figura 10. Biósferas.

Fuente: Fotografía tomada en el Instituto Educativo Distrital Nidia Quintero de Turbay durante el proyecto Ciencia cotidiana y los domingos de la Ciencia (2012)@ MCJ.

\section{Hace mucho, mucho tiempo...}

Obra de títeres que por medio de la narrativa y la fantasía, sin olvidar el conocimiento científico que la nutre, promueve el interés en temas de evolución y paleontología, en niños principalmente de ciclos escolares uno y dos. La obra Hace mucho, mucho tiempo... de mi autoría, trata de un paleontólogo y su curiosa asistente de campo quienes se embarcan en un viaje de imaginación hacia el pasado, basado en los restos fósiles que han encontrado en sus excavaciones. Durante dicho viaje nadan por los mares del Cámbrico, donde ven trilobites y al terrible Anomalocaris; irán más adelante en el tiempo, a la llamada era de los dinosaurios, y serán testigos de la interacción de mamíferos reptiloides, dinosaurios y pterodáctilos, hasta presenciar el gran impacto del meteorito que acabó esa fantástica era. La obra termina con una reflexión sobre la actual extinción causada por las actividades humanas.

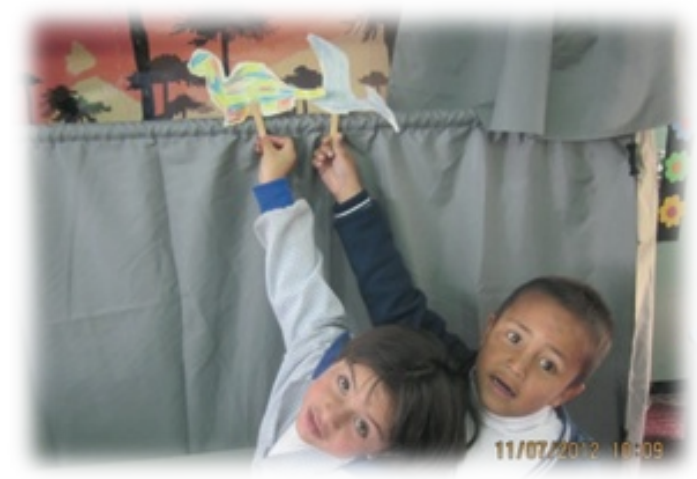

Figura 11. Hace mucho, mucho tiempo... Fuente: Fotografía tomada en el Instituto Educativo Distrital Los Alpes durante el proyecto Programa Escuela Ciudad Escuela Expediciones Pedagógicas (2012)@ MCJ.

Como actividad lúdica, cada participante realiza títeres de seres prehistóricos, mediante el uso de moldes, y al finalizar la obra los titiriteros responden preguntas sobre la historia, y de paso aprovechan para relacionar conceptos evolutivos con los acontecimientos sucedidos a los personajes. Esta estrategia resultó motivadora para los participantes lo que se vio reflejado en la cantidad de preguntas realizadas por los mismos. A propósito, considero que presentar conocimiento a través de historias es una estrategia poco explorada en las aulas y con gran potencial educativo.

\section{MiniTalleres}

Se entienden como actividades cortas (de cinco a quince minutos) con la mediación de un tallerista que generalmente propone una actividad lúdicay una explicación paralela de la misma. Este tipo de actividades fueron ofrecidas a personas de diferentes ocupaciones y edades, y acompañaron las exposiciones itinerantes y las ferias científicas donde cualquier persona de la comunidad visitada podía interactuar con los objetos y participar de los miniTalleres sin ningún costo.

MiniTaller de fósiles: Mediante eluso de yeso odontológico, agua y figuritas de animales, especialmente dinosaurios, los participantes simulan el proceso de fosilización, y, de paso, se llevan una manualidad. El tallerista aprovecha, mientras hacen la manualidad, para explicar que la actividad viviente deja huellas en el registro geológico. 


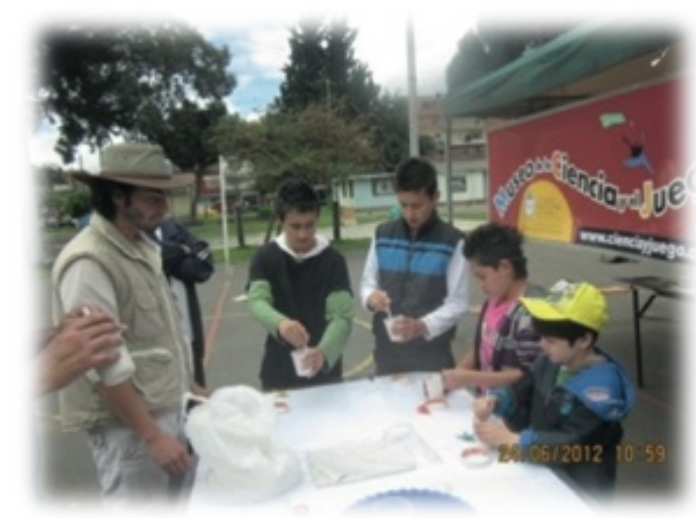

Figura 12. MiniTaller de fósiles.

Fuente: Fotografía tomada en el Junta de Acción Comunal de Álamos Norte durante el proyectoCiencia cotidiana y los domingos de la Ciencia (2012)@ MCJ.

MiniTaller de animales prehistóricos: Por medio de armables tridimensionales, los jugadores van armando y aprendiendo sobre la estructura y la biología de estos antiguos seres. Existen dos armables en el mcj:

-Spinosaurus ludus. Armable tridimensional que representa una especie hipotética perteneciente al grupo de los espinosaurios. Existen dos versiones: una de gran formato (armado y "puesto en pie" mide poco más de dos metros, aproximadamente) y uno de mediano formato (armado y "puesto en pie" mide unos $45 \mathrm{~cm}$ ).

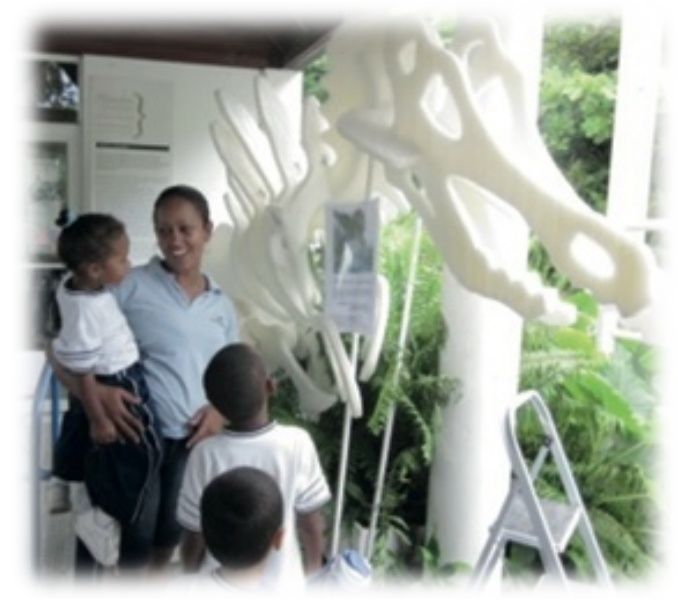

Figura 13.Spinosaurus ludus.

Fuente: Fotografía tomada en el Jardín Botánico de la Sede Caribe de la Universidad Nacional de Colombia en San Andrés Isla durante el Mes de la Ciencia y la Tecnología(2011)@ MCJ.

-Meganeuropsis. Armable tridimensional que tiene una envergadura de aproximadamente noventa centímetros,tamaño que pudo alcanzar la Meganeuropsis real, hasta ahora el insecto volador más grande identificado que ha existido sobre la faz de la Tierra (característica que siempre impresiona a los visitantes).

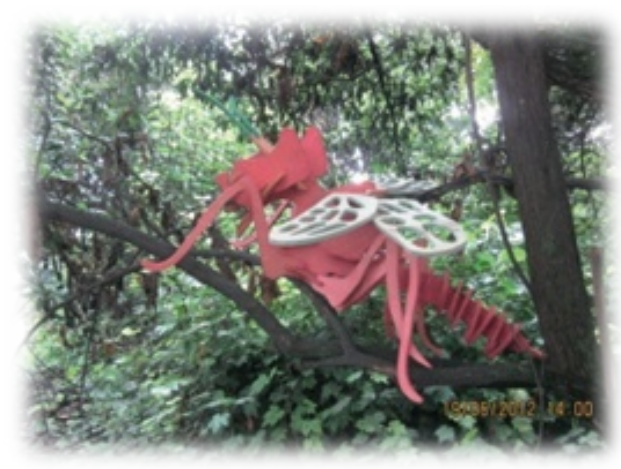

Figura 14. Meganeuropsis.

Fuente: Fotografía tomada en el Humedal Santa María del Lago durante la visita del MCJ durante el proyecto Ciencia cotidiana y los domingos de la Ciencia (2012)@ MCJ.

En las "arcas" del MCJ se cuenta con 78 objetos de exposición relacionados con la biología (incluyendo réplicas) que pueden ser solicitados de manera gratuita, ya que se propende a promover una divulgación científica incluyente. Gracias a esta filosofía de inclusión del museo, las diferentes exposiciones interactivas son utilizadas continuamente por instituciones, especialmente colegios, y aunque el número de personas que entrarán en contacto con los diferentes objetos relacionados con la biología es difícil de estimar, siempre irá en aumento. Los objetos de la Maleta Rumbo UN (El árbol, La historia de la vida, Fractales en la naturaleza y EncADeNando) son los que más serán utilizados a nivel nacional, ya que dos ejemplares de cada uno hacen parte de maletas administradas por las ocho sedes de la Universidad Nacional de Colombia, varias de ellas localizadas en sitios de frontera (San Andrés Isla, Tumaco, Arauca, Leticia).

Los objetos y las actividades aquí mencionados son un pequeño aporte en divulgación de la biología a través de la lúdica en Colombia y tienen un componente fuerte en teoría evolutiva, constituyendo valiosas experiencias en la enseñanza de la evolución, teniendo en cuenta que, como indicaAraujo y Roa (2011), existe escasa información sobre actividades relacionadas con estos temas en el país. Estos talleres y objetos irán evolucionando, migrando, y generando innovaciones expositivas, siempre y cuando las condiciones para su gestación no se vean limitadas. 


\section{Agradecimientos}

Quiero agradecer a todas las entidades que posibilitaron el desarrollo de los objetos y talleres mencionados (Alcaldía Local de Engativá, Sede Tumaco de la un, Colsubsidio, Dirección Académica de la UN) o por proporcionar espacios para la ejecución de los proyectos (Jardín Botánico de la Sede Caribe de la un, Secretaría de Educación del Distrito, Jardín Botánico José Celestino Mutis y Juntas de Acción Comunal de Álamos Norte, El Lujan, Alameda y Ciudadela Bachué); al equipo interdisciplinario del Museo de la Ciencia y el Juego de la Universidad Nacional de Colombia por constituir un espacio donde la ciencia, la lúdica y la creatividad se entrelazan para formar sinergias cuyos efectos son difíciles de determinar, pero positivos y divertidos para la diversa comunidad colombiana en general; y a Ángela Martínez, Coordinadora del MCJ, así como a los misteriosos jurados y al corrector de estilo de la revista, por sus pertinentes comentarios del presente texto.

\section{¿El fin de un viaje?}

Este naturalista ha terminado un viaje con el M. C. J. Ludus, que esperamos no sea el último, ya que siempre es grato ver el mar desde su cubierta. Los tesoros enterrados en las viejas catacumbas hablan de los viajes que este barco ha realizado a lo largo de su historia que ya bien larga ha sido. El navío seguirá navegando por los impredecibles mares de la divulgación científica. Encallará. Su tripulación disminuirá. Se enfrentará contra monstruos de diversas tallas. El capitán a veces creerá no ver el horizonte. Pero eso ya lo ha enfrentado antes. EIM. C. J.Ludus, como su capitán, también es un viejo lobo de mar, y difícilmente naufragará. Ya sé que nunca has estado en Ítaca. ¡No importa!, ¡sigue tu rumbo hacia ella!

\section{Referencias}

Andrade, E., Bueno, M. L., Burbano, C., Chaparro, A., García, L. F., Matta, N., Usaquén, W. (2006). Manual de guías de laboratorio de genética mendeliana, poblaciones, citogenética y genética molecular. Bogotá: Universidad Nacional de Colombia, Faculta de Ciencias.

Annis, S. (1986). El museo como espacio de la acción simbólica. Museum 38(3), 168-171.

Araujo, R. y Roa, R. (2011). Enseñanza de la evolución biológica: Una mirada al estado del conocimiento. Bio-grafía, 4(7), 15-35.

Burton, S. R. y Dobson, C. (2009). Spork \& Beans: Addressing Evolutionary Misconceptions. The American Biology Teacher, 71(2), 89-91.

Caillois, R. (1986). Los juegos y los hombres. México: Fondo de Cultura Económica S. A.

González-Medina, J. P. (2011). Entre genes y emociones. Museo Lúdica, 14(26), 84-89.

Granada, E., Orozco, M., Bonilla, A. y Fernández, F. (1995). Cartillas de Re/Creo. Biología. Bogotá: Universidad Nacional de Colombia, Facultad de Ciencias.

Montaldo, S. (2001). Semiótica y pedagogía: una articulación productiva. Cuadernos, 17, 321-340. 